Certificates.-Every candidate must forward together with his form of entry the following certificates: *

1. A certificate of having spent at least two years in the study and practice of Ophthalmology at a teaching school or schools approved by the University, of which one year at least must have been subsequent to obtaining the M.B., B.S. Degrees in this University.

2. A certificate of having held during this time for at least six months an approved appointment + in the Ophthalmic department of a general hospital recognized by the University for the purpose, or at an Ophthalmic hospital recognized by the University.

Details of Examination.-The examination will consist of :

Two papers in Ophthalmology (in one of which there may be included a case for commentary).

One paper in the Principles of Surgery.

A clinical examination.

One paper in the Anatomy and Physiology of the Eye and other parts concerned in Ophthalmology (including Physiological Optics).

One paper in the Pathology of the Eye and other parts concerned in Ophthalmology.

An oral examination.

Candidates shall not be approved by the examiners unless they have shown a competent knowledge in all the subjects of the examination.

\title{
Elliot Ophthalmic School
}

An event of more than local importance took place recently when Her Excellency Lady Willingdon opened the Elliot Ophthalmic School in connection with the Government Hospital in Madras. This is the outcome of the decision reached by the Government of Madras in 1916 to give theoretical instruction and practical training in ophthalmology side by side in the same building. The Government accordingly sanctioned the construction of a building, at an estimated cost of Rs. 75,750, within the grounds of the Ophthalmic Hospital, and determined to name it after Lieut.-Colonel R. H. Elliot, in recognition of the services rendered by him to ophthalmology in Madras and elsewhere. There is accommodation in the new school for 120 students and graduates, and the tuition will be in the hands of Lieut.-Colonel H. Kirkpatrick and his successors. The section of ophthalmology. in the medical college will be

* (Internal regulations only.) Candidates entering for this examination under Statute 129 will also be required to send in a certificate of having completed the prescribed course of study.

$\dagger \mathrm{A}$ list of these appointments may be obtained on application to the Academic [or External] Registrar. 
transferred to the new school. The building is divided into two floors, of which the first includes a large waiting hall, lecture theatre (fitted with an epidiascope), a dark room for thirty students, and luncheon rooms. The second floor is provided with a large museum, liberally furnished with models, pictures, and stereoscopic views of external diseases of the eye. There are pathological specimens and microscopical slides are also on exhibit. Attached to the museum is a studio with a dark room. A library and a room for practising operations upon dummy eyes are also provided. The silver key used in formally opening the building had inscribed upon it "In tenebras lucem."

\section{The Illumination of Mines}

The interesting account of the discussion on the illumination of mines which we were enabled to publish last month by the kindness of the Illuminating Engineering Society, shed considerable light on what expert opinion agreed in considering the best form of lamp. That opinion was largely in favour of the electric lamp. The discussion was, and naturally so, mainly confined to medical men and representatives of lamp makers, and little was said about the opinions of the user of the lamp, the miner himself. Mr. J. George said that in one district in Scotland the miners have the best oil lamp to go down with for nothing, but they prefer to pay 9d. per week and have the electric lamp. If further corroboration of this statement is needed it may be found in a note in the Electrical Review for April 9th, p. 466, "Electric Lamps in Mines. As a protest against the non-provision of electric lamps in the minewhich they claim give more safety and a better light below ground $-1,400$ men employed at the Tirpentwys Colliery, Pontypool, have given a fortnight's notice to cease work." We are indebted to the courtesy of Mr. L. Gaster, the Hon. Secretary of the Illuminating Engineering Society, for the above reference. Although it must be admitted that the miners are only too ready to strike for any cause at the present time, the above statement would certainly show that they approve of the electric lamp.

\section{Cobalt Glass in Refraction Work}

The use of cobalt glass as an occasional aid in refraction has been known for many years, and is the subject of casual reference in some text-books. It is usually spoken of as being of great scientific interest but of little practical use; but occasionally in dealing with intelligent patients it proves of great service. Its 